\title{
A máscara e o que pode ser dito: mecanismos de silenciamento ontem e hoje e as fake news
}

\author{
The mask and what can be said: silencing mechanisms \\ yesterday and today and fake news
}

\author{
Veronica Santana Queiroz \\ Doutoranda do Programa de \\ Pós-Graduação em Bioética, \\ Ética Aplicada e Saúde \\ Coletiva (PPGBIOS)/UFRJ- \\ UERJ-FIOCRUZ-UFF. \\ veronicasqueiroz@gmail.com
}

Recebido em: 10/02/2020

Aceito em:05/04/2020
Resumo

As fake news têm sido usadas como estratégias políticas para a disseminação de informações falsas fazendo uso das mídias sociais com a finalidade de manipular opiniões em detrimento do silenciamento de fatos e de vozes historicamente mortificadas. Esse fenômeno tem como correlato as máscaras coloniais que serviam para impor o silenciamento nos sujeitos negros escravizados, em especial, nas mulheres. A hipótese central do artigo é que o mecanismo de silenciamento que ora foram as máscaras coloniais foi atualizado na forma das fake news persistindo os rastros da colonialidade. Trazer à superfície versões da história que foram ocultadas é uma aposta para provocar fissuras nas máscaras.

Palavras-chave: máscaras coloniais, fake news, silenciamento, fissuras.

\section{Abstract}

Fake news have been used as political strategy to disseminate fake information by making use of social media with the purpose of manipulating opinions at cost of the silencing of facts and from other historically mortified voices. This phenomenon is related to colonial masks which had the purpose of silencing enslaved black people, especially the women. The central hypothesis of the article is that the silencing mechanism that once were the colonial masks have been updated as fake news where coloniality traces still persist. Revealing versions of the history which have been hidden is an attempt to cause fissures to those masks.

Keywords: colonial masks, fake news, silencing, fissures. 


\section{Introdução}

O presente artigo é fruto de algumas provocações que me afetaram no ano de 2019. Destaco, em especial, dois eventos: primeiro, questões pessoais muito marcantes que fizeram me afirmar como uma intelectual negra e, segundo, a participação na VI Jornada de Bioética do Programa de Pós-Graduação em Bioética, Ética Aplicada e Saúde Coletiva (PPGBIOS em associação com a UFRJ, UERJ, UFF e FIOCRUZ) realizada na UERJ. Na mesa redonda cujo tema foi "Justiça, opressões e pós-verdade" apresentei algumas reflexões embrionárias que resultaram mais amadurecidas neste artigo, recebendo ao final felicitações de professores e amigas, bem como sugestões para a publicação do conteúdo exposto por mim na mesa, o qual consideraram muito relevante. Além disso, o processo de construção da minha fala na Jornada me provocou muitas reflexões e transformações internas me fazendo acreditar que seria importante publicar tais inquietações.

Este artigo objetiva analisar o fundamento das máscaras coloniais como forma de silenciamento de sujeitos negros escravizados no período colonial e, na perspectiva da colonialidade, analisar como essa prática colonial se atualizou em novos mecanismos tais como a fake news. Propõe como forma de provocar "rachaduras" nas "mordaças contemporâneas" tornar visíveis versões da história a partir de vozes e olhares contra hegemônicos, isto é, vozes e olhares não brancos, aqui, destacados pelas mulheres negras.

A modernidade e a concepção de democracia ocidental que cultivamos foram e estão sustentadas no racismo (MBEMBE, 2014; 2018; ALMEIDA, 2019a; 2019b; 2019c) que se atualiza com o passar do tempo. Sendo assim, é possível afirmar que as práticas racistas e coloniais se adaptam aos novos cenários exigindo renovadas ações antirracistas.

Autores como Foucault $(2005 ; 2009)$ e Mbembe (2018) delineiam como algumas tecnologias de poder transformadas em políticas de Estado ou em poderes paralelos são construídas para fazer viver alguns grupos e fazer morrer outros. A morte aqui, pode ser de fato ou simbólica; de fato, quando há a eliminação física do sujeito; simbólica quando há a mortificação do sujeito em vida, isto é, a anulação da existência transformando-o em objeto e em vidas sub-humanas. É o que o Mbembe (2018) chama de "mortos-vivos" (p. 71) dadas as condições as quais populações inteiras sofrem com o necropoder e a sua criação de "mundos de morte" (MBEMBE, 2018, p. 71) ou uma "política da matabilidade" (LIMA, 2018). O silenciamento é uma forma de morte simbólica. No caso brasileiro, negras/os e indígenas pertencem ao grupo destinado a morrer ou, no mínimo, suas vidas são tornadas miseráveis ou inviáveis.

Mbembe (2018) vai chamar de necropolítica as "formas contemporâneas que subjugam a vida ao poder da morte" (p. 71), isto é, estratégias cujos objetivos sejam provocar a morte física e/ou simbólica de grupos ou fazer com que tais grupos mantenham um status de desumanidade. Essas forças de morte não são empreendidas necessariamente pelo Estado, mas também por forças paralelas que disputam o poder. $\mathrm{Na}$ concepção da necropolítica (MBEMBE, 2018, p. 71), as políticas de terror e as políticas de morte se destinam a determinadas populações ${ }^{1}$ como forma de controle e de não-contaminação ${ }^{2}$ de determinada população que deve ser preservada.

\section{Racismo e a máscara colonial: quem pode falar?}

Nesta subseção, trabalharei com a perspectiva teórica de Grada Kilomba especialmente com o seu livro Memórias da Plantação - episódios do racismo cotidiano (2019). Trarei elementos de Silvio Almeida com o livro Racismo estrutural (2019) e Lima (2018) dialogando com Kilomba (2019) e Fanon (2008).

1 No caso brasileiro poderíamos citar algumas populações “indesejáveis", alvos do necropoder: os dependentes de drogas, os "loucos", as pessoas em condição de rua, a população carcerária, a população LGBTQI+, as profissionais do sexo, os pobres, os negros e as mulheres negras, os/as indígenas.

2 As noções de contaminação social e degeneração racial foram desenvolvidas por teorias eugênicas racistas pseudocientíficas no século XIX na Europa que afirmavam que determinados grupos "decadentes" (leia-se, pobres, desviantes, os considerados anormais) poderiam "contaminar" outros grupos considerados "melhores" e "superiores". Conferir em Foucault (2005). 
Apresento duas definições de racismo que considero importantes. A primeira, de Kilomba (2019, p. 7576), caracteriza o racismo descrevendo três características: (1) a construção da diferença; (2) diferenças essas ligadas a valores hierarquizados e, (3) ligadas a relações de poder. A construção da diferença diz respeito a adotar um grupo que se definiu como norma, sendo os demais grupos classificados como "anormais" a partir da ficção da ideia de raça. Assim, o ponto de referência é o branco, sendo os não-brancos, em particular as/os negras/os, tomados como "dissemelhantes" em um processo de discriminação racial a partir da branquidade Associado aos grupos "diferentes" há também a construção da ideia de valores como a inferioridade, ou seja, essa dissonância constitui em si seres "inferiores", "inadequados", "anormais", "perigosos", "problemáticos", etc. Nesse caso, a construção da diferença combinada com valores hierárquicos forma o que se chama de preconceito. Kilomba (2019) assinala que ambos os processos citados acima são permeados pelo poder, criados pelo grupo racial dos brancos, como forma de se perpetuarem no poder. Ela diz: "Por fim, ambos os processos são acompanhados pelo poder: histórico, político, social e econômico. É a combinação do preconceito e do poder que forma o racismo. E nesse sentido, o racismo é a supremacia branca" (KILOMBA, 2019, p. 76, grifos da autora)

Kilomba (2019) enfatiza que o racismo é a supremacia branca pois este é o grupo que mais ocupa lugares de poder e de acesso a recursos valorizados tais como representação política, educação, saúde etc., e a que mais performa e pratica o racismo contra o grupo negro. O poder branco estabelece "a epidermização da inferioridade" (FANON, 2008, p. 28).

A segunda definição a ser destacada é a de Almeida (2019, p. 32), que considera o racismo

uma forma sistemática de discriminação que tem a raça como fundamento, e que se manifesta por meio de práticas conscientes e inconscientes que culminam em desvantagens ou privilégios para indivíduos, a depender do grupo racial ao qual pertençam.

Almeida (2019) aponta que o racismo acontece quando, dependendo da raça, estabelecem-se desfavorecimentos ou favorecimentos. O autor não define nenhuma raça historicamente hegemônica nas relações de poder como faz Kilomba (2019) na sua obra.

O livro da Grada Kilomba Memórias da plantação - episódios do racismo cotidiano (2019) me inspirou fortemente a pensar sobre a reencenação do colonialismo na atualidade, principalmente no contexto brasileiro. Kilomba é portuguesa, de Lisboa, e o referido livro é o resultado da sua tese de doutorado defendida em Berlim, na Alemanha, e publicada como livro em 2008. Nele, ela entrevista mulheres negras, enfatizando duas, uma afro-alemã e outra, afro-estadunidense, e os seus relatos sobre as experiências subjetivas com os racismos que sofreram no cotidiano, fazendo um diálogo entre o racismo colonial e o racismo atualizado no presente como uma reencenação do período colonial, considerando, dessa forma, o racismo como atemporal. O racismo cotidiano é também uma "realidade traumática" (KILOMBA, 2019, a partir do subtítulo A Ferida, p. 37). porque recoloca o indivíduo negro numa cena colonial e com isso, a violência, a objetificação e a subalternidade são repetidamente sentidos. Kilomba faz uma análise dos relatos a partir da psicanálise de Frantz Fanon no livro Pele Negra, Máscaras Brancas (2008) e o primeiro capítulo de Memórias da Plantação (2019) chama-se A máscara.

De acordo com Kilomba (2019), a máscara é um símbolo das políticas coloniais e de medidas brancas sádicas para silenciar a voz dos sujeitos negros durante a escravização. Olhando as imagens de pessoas negras escravizadas com a máscara, a sensação é de sufocamento, de embaçamento da visão, de impedimento da fala, de mortificação. Por outro lado, as orelhas são deixadas de fora da máscara, como se tivessem a necessidade de ouvir o que o colonizador tem a dizer. É uma imposição de uma mudez e uma escuta forçadas.

A branquidade é um conceito associado aos valores da supremacia branca onde os indivíduos lutam pela manutenção de seus privilégios estruturais, na crença na superioridade de seus indivíduos em todos os níveis e na pureza da raça branca, dentre outros aspectos. Ver diferença entre branquidade e branquitude em Jesus (2012). 
Segundo Kilomba (2019), a boca, no âmbito do racismo, "se torna o órgão da opressão por excelência representando o que os brancos colonizadores queriam controlar e, consequentemente o órgão que, historicamente, tem sido severamente censurado" (p. 34).

Kilomba (2019) faz as suas reflexões provocando muitas inquietações:

Por que o sujeito negro tem de ficar calado? O que poderia o sujeito negro dizer se ela ou ele não tivesse a sua boca tapada? E o que o sujeito branco teria de ouvir?. Existe um medo apreensivo de que, se o sujeito colonial falar, a/o colonizadora/or terá de ouvir. Seria forçada/o a entrar em uma confrontação desconfortável com as verdades da/o "Outra/o". Verdades que têm sido negadas, reprimidas, mantidas e guardadas como segredos. [...]. Segredos como a escravização. Segredos como o colonialismo. Segredos como o racismo (KILOMBA, 2019, p. 41, grifos da autora).

Dessa forma, o colonizador teria que entrar em contato com outras versões da história que muitas vezes poderiam lhe causar vergonha, mas sobretudo, que ameaçariam o seu poder. Kilomba (2019) com suas perguntas inquietadoras demonstra uma dinâmica de fala (do branco), de silenciamento (do/a negro/a), de impor o ouvir (ao/à negro/a) e provoca pensarmos como seria inverter essa dinâmica: o que o/a negro/a teria para falar? O que os/as brancos/as teriam que ouvir? Essa inversão sugere dar voz àqueles/as que historicamente têm sido silenciados/as e invisibilizados/as. É dar espaço para as críticas ao racismo estrutural imperante no Brasil, é responsabilizar os/as brancos/as e as instituições embranquecidas pela manutenção de privilégios em detrimento de prejuízos causados aos grupos não-hegemônicos, é provocar a fragilização do poder do grupo hegemônico ${ }^{4}$ e pressionar por políticas de reparação. É causar fissuras nas máscaras impostas ao povo negro pelos brancos/as.

Apresento abaixo algumas imagens de máscaras coloniais e outros objetos de tortura5 ${ }^{5}$.

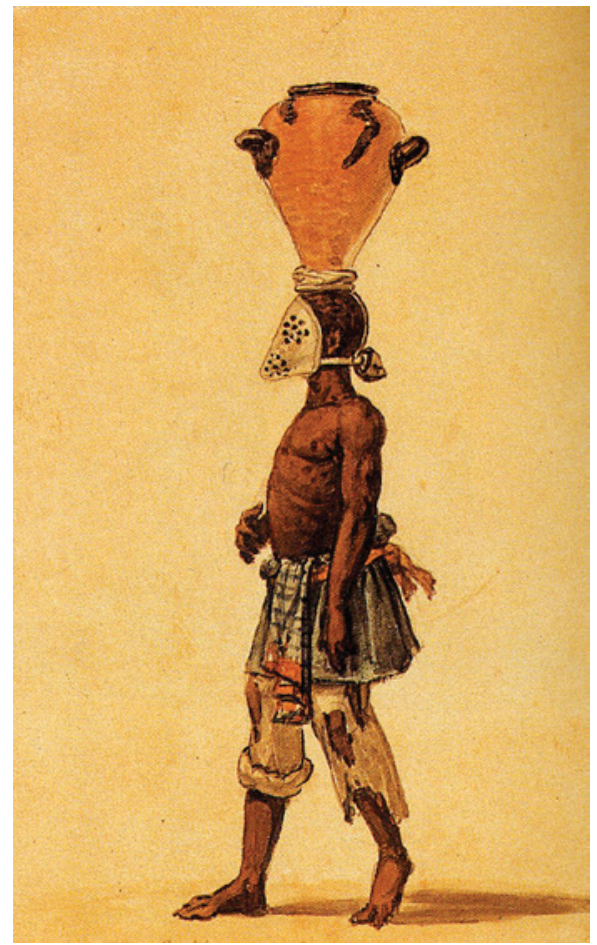

Imagem 1 - Jean B. Debret - Máscara de ferro branca que se faz o negro vestir (tradução livre). Brasil - 1830

4 Geralmente o grupo hegemônico é formado por um tipo de racionalidade baseada no norte global, racista, capitalista, branca, colonial e patriarcal (SANTOS, 2018; KILOMBA, 2019; RIBEIRO, 2019; CARNEIRO, 2018).

5 As imagens de 1 a 4 foram retiradas do seguinte site, na seção Physical Punishment, Rebellion, Running Away (em tradução livre: Punição física, Rebelião e Fuga): <http://www.slaveryimages.org/s/slaveryimages/item-set/36>. Acesso em: agosto de 2019. 


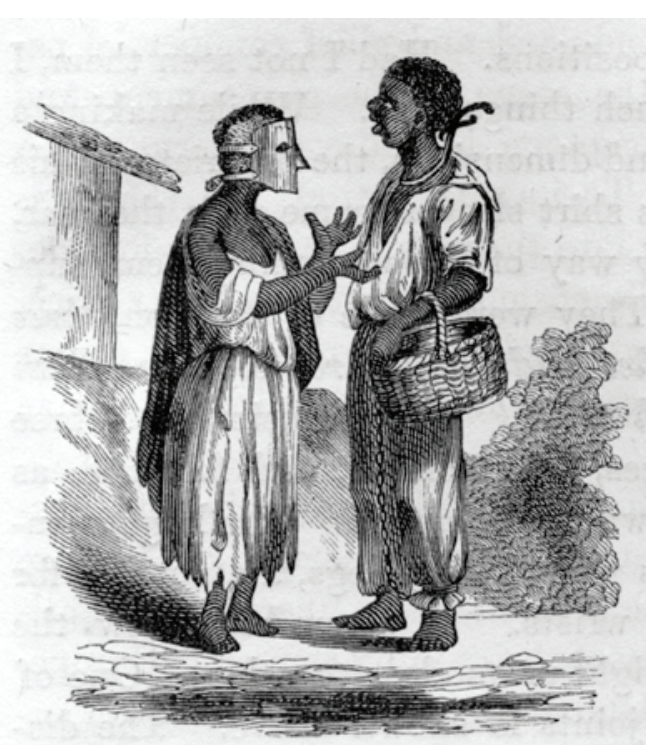

mask is to hinder him or her from mouth, below which the metal is which there is no opening.
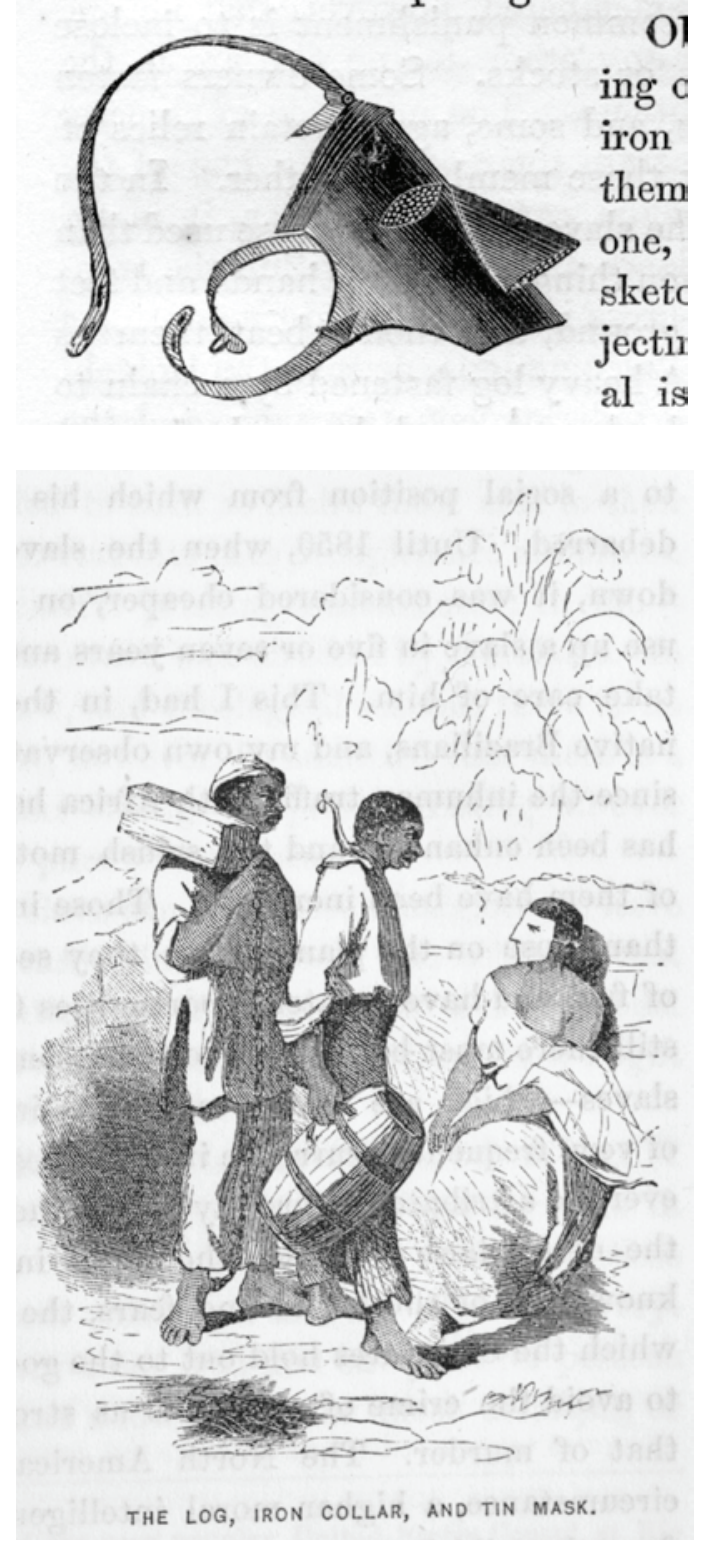

Imagem 2 - Thomas Ewbank - (sem título) - Observa-se a máscara facial de ferro no rosto da mulher, à esquerda, e o colar com corrente ligada ao tornozelo do homem, à direita. Brasil, 1846.
Imagem 3 - Daniel P. Kidder - Título: Punições para fugitivos, Rio de Janeiro, Brasil, década de 1850 (tradução livre). Observa-se a corrente com tronco presa ao tornozelo, colar e máscara no rosto da mulher.Rio de Janeiro, 1850. 


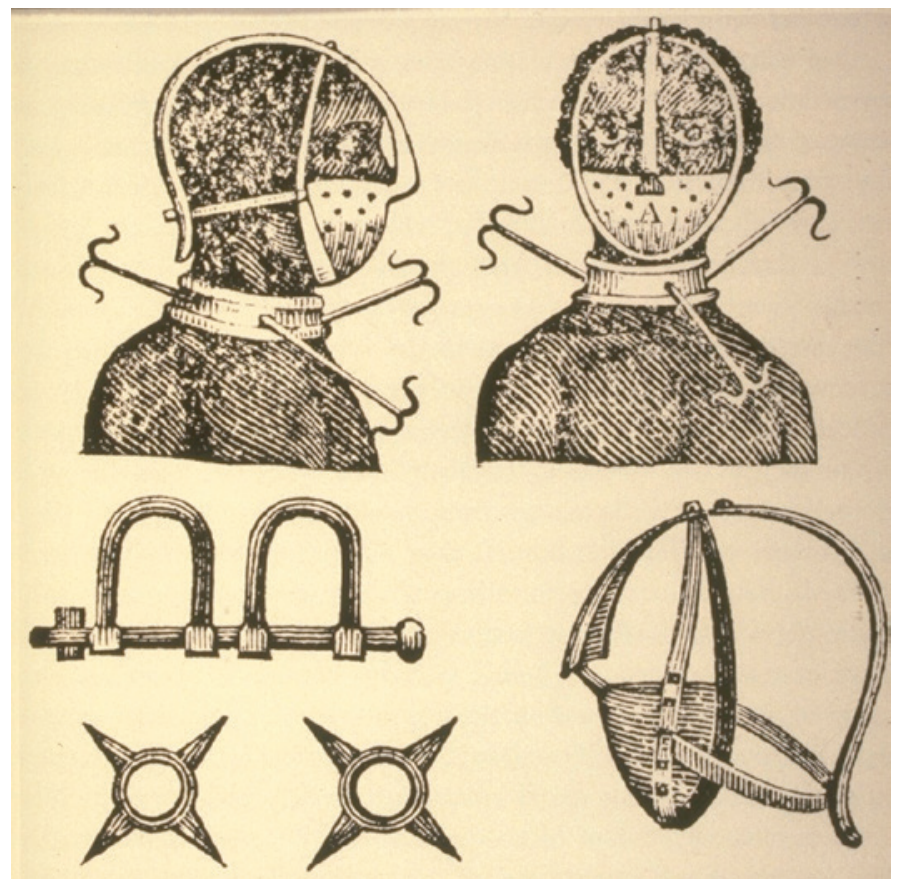

Imagem 4 - Thomas Branagan. Título: Máscara de ferro, colar para o pescoço, algemas para os tornozelos e esporas, século XVIII (tradução livre). Costa da África, século XVIII.

As máscaras que tomam o rosto inteiro eram frequentemente usadas especialmente nas mulheres ${ }^{6}$. Federici conta no seu recente livro Mulheres e a caça às bruxas (2019) sobre máscaras do século XVI na Escócia conhecidas como scold's bridle, gossip bridle ou branks (rédea ou freio das "rabugentas") que eram usadas em mulheres que "falavam demais", "mentiam", "fofocavam". Na estrutura da máscara havia uma espécie de placa de metal com espetos que ficava inserida dentro da boca, entre o palato e a língua da vítima, de modo que, se as mulheres tentassem falar, machucariam a língua. Essa mesma estrutura é descrita nas máscaras coloniais e impedia inclusive da/o escravizada/o engolir a própria saliva ${ }^{7}$. As máscaras de ferro ficavam tão aquecidas que frequentemente a pele grudava no metal ${ }^{8}$. No contexto europeu, elas eram impostas principalmente a mulheres pertencentes a classes baixas e consideradas "importunas" ou "rabugentas". Quando suspeitas de bruxaria, eram forçadas a andar publicamente com esse instrumento de punição e tortura para mostrar às demais mulheres o que lhes aconteceria se não fossem obedientes aos seus maridos e/ou não se comportassem conforme os costumes patriarcais da época.

Na versão oficial no contexto colonial (a versão segundo o ponto de vista do/a colonizador), a máscara era usada para evitar que os escravizados comessem cana-de-açúcar ou cacau nas plantações enquanto trabalhavam, sendo utilizada também para coibir a embriaguez e/ou para não comerem terra. Outra versão, a não-oficial, sob o ponto de vista do colonizada/o, a máscara era usada para implementar o silenciamento, $\mathrm{o}$ medo, a tortura, o terror. Aliás, $\mathrm{o}$ ato de comer terra acontecia como uma forma desesperada de cometer o suicídio (PEREIRA, 2007, p. 102; ODA, 2008), para matar a fome (ODA, 2008), dentre outras hipóteses.

A máscara simboliza uma política de dominação e seu regime de silenciamento: "quem pode falar?”, “o que acontece quando falamos?" e "sobre o que podemos falar?". Assim, podemos pensar que essa política de apagamento impôs a invisibilidade de histórias coletivas, de culturas, de versões da história de civilizações não-eurocentradas, de identidades, de epistemologias e cosmovisões do Sul do mundo, dentre outros. Kilomba (2019, p. 35-36) nos apresenta o exemplo da "escrava Anastácia" que teve a sua história e a sua identidade

6 De acordo com o site consultado nas descrições das seguintes imagens: <http://www.slaveryimages.org/s/slaveryimages/ item/2592> e <http://www.slaveryimages.org/s/slaveryimages/item/1298>. Acesso em: agosto de 2019.

7 De acordo com o site consultado na descrição da seguinte imagem: <http://www.slaveryimages.org/s/slaveryimages/ item/1298>. Acesso em: agosto de 2019.

8 De acordo com o site consultado na descrição da seguinte imagem: <http://www.slaveryimages.org/s/slaveryimages/ item/1298>. Acesso em: agosto de 2019. 
apagadas com a escravização. A autora aponta algumas especulações e diferentes versões contadas sobre a vida e a história de Anastácia.

Algumas contam que Anastácia seria filha de uma família real Kimbundo, na Angola, que foi sequestrada e levada para a Bahia. Outras alegam que ela teria sido uma princesa Nagô/Yorubá antes de ter sido capturada como escravizada. Há os que afirmam que ela teria nascido na Bahia. O nome de Anastácia foi o nome dado na escravização, sendo seu nome africano desconhecido. Ela teria sido forçada a usar um colar de ferro muito pesado, além da máscara facial que a impedia de falar. As razões para o castigo divergem, alguns relatam que seria por causa do seu ativismo político auxiliando nas fugas de escravizados; outros dizem que ela havia resistido aos abusos do colono branco; outros afirmam que teria sido por ciúmes de uma sinhá que temia a sua beleza. Conta-se também que Anastácia possuía poderes de cura e realizou milagres. Depois de passar por um intenso sofrimento, Anastácia morreu de tétano por causa do colar de ferro preso ao pescoço que provavelmente a feria.

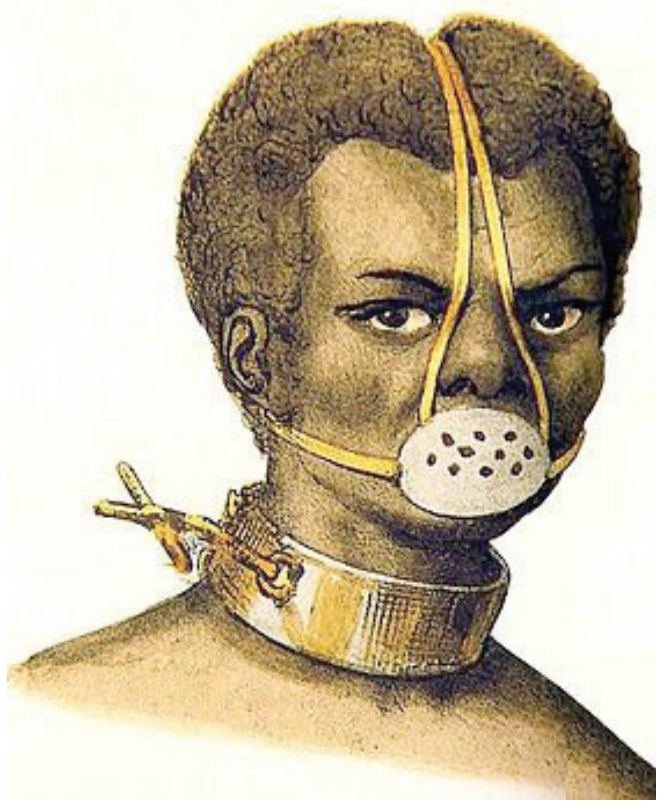

Imagem 5: Escrava Anastácia. Fonte: Google Imagem.

No ano de 2019, o artista Yhuri Cruz (@yhuricruz), criou a "Anastácia Livre”. O texto que acompanha a publicação da imagem na conta do Instagram do autor diz:

Anastácia Livre é uma viagem no tempo. É voltar ao passado e libertar essa mulher negra escravizada que veio do Congo no século XVIII e foi condenada à mordaça pelo resto da vida por lutar contra a um homem branco que a violentou sexualmente. Se tornou a "escrava santa" por sua firmeza, mas refém à uma iconografia colonial. Em Monumento à voz de Anastácia, trabalho que exponho hoje, ergo um monumento à voz dela. Uma voz negra, feminina, de luta pela existência. (CRUZ, 2019, grifo do autor).

Retomando as reflexões de Kilomba (2019) quando analisa a boca e a voz dos sujeitos amordaçados, na postagem do dia 19 de julho de 2019, em sua conta no Instagram Yhuri Cruz, (@yhuricruz) diz: “Quando tive a idéia de criar a Anastácia Livre pensava na voz dela. Na boca e, principalmente no som, nas palavras, no canto que sua boca emitiria quando livre. Fiz um monumento à sua voz. E sem criar expectativas, creio ter feito um Monumento à voz Negra."

9 Disponível em: <https://www.instagram.com/p/B0Gb77gp6J2/?igshid=rgv0sj2t1oj8>. 


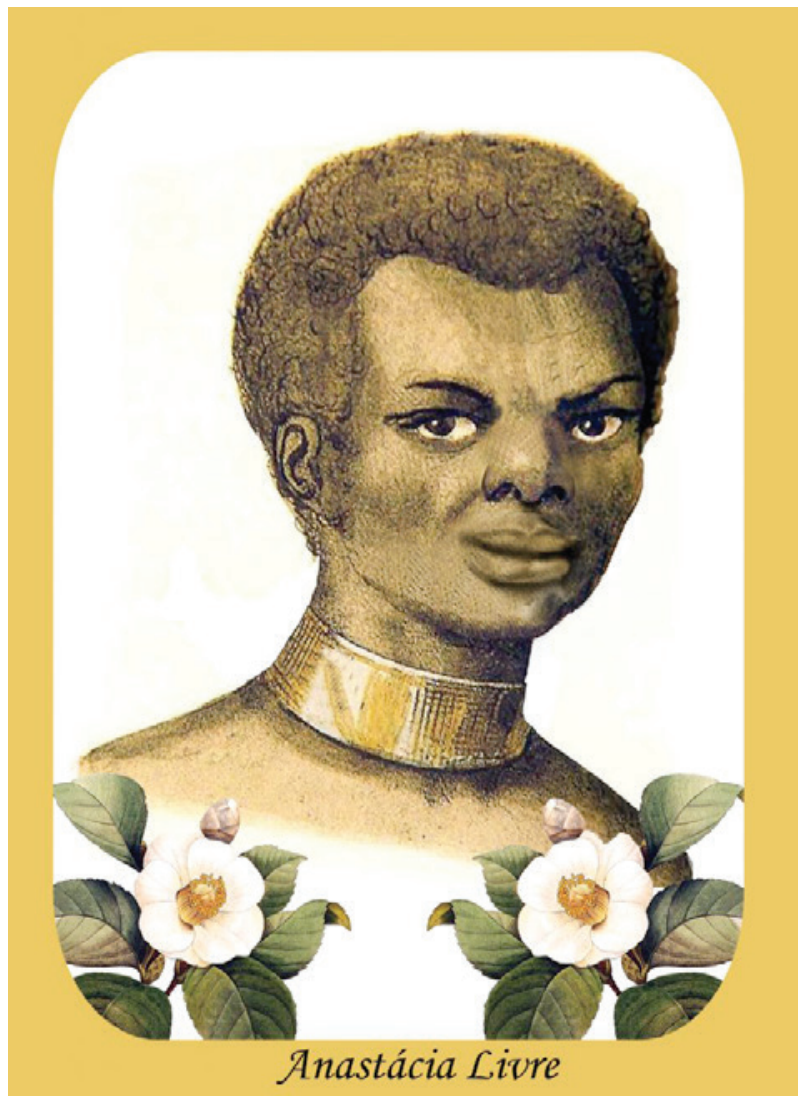

Imagem 6: Yhuri Cruz - Título: Anastácia Livre.Rio de Janeiro, 2019. Fonte: Google Imagem.

Como vimos, o racismo se estabelece também e sobretudo nas relações sociais. Para o indivíduo negro a relação com a branquidade o coloca numa condição de subalternidade e silenciamento desde a infância. Fanon analisa a sociogênese do racismo na sua obra Pele Negra, Máscaras Brancas (2008), que seriam as condições sociais e culturais para a estruturação das práticas racistas e consequentemente na formação da subjetividade negra, isto é, o racismo não estaria somente localizado nos indivíduos, mas estaria sendo gestado e fomentado socialmente. Kilomba (2019), como dito no início desta subseção, assinala a atemporalidade do racismo, ou seja, ele se reatualiza e se adapta ao tempo, assim, o racismo é sociogênico e atemporal gerando constantes traumas. Lima e Andrade (2020) constatam:

O trauma colonial marcado por uma colonialidade reatualizada cotidianamente exigem um deslocamento da dimensão estritamente individual e intrapsíquica, para pensar os processos traumáticos que atravessam as experiências de negritude como indissociáveis do mundo e, consequentemente, da hegemonia branca. Para pensar e discutir sobre as subjetividades negras é imprescindível o entendimento da violência da linguagem colonial/colonialista que reencena a possibilidade de desumanização das populações colonizadas. (Ibid., 2020 p. 92)

Nesse sentido, a mudança da linguagem colonial para uma linguagem decolonial onde as "amarras" são retiradas das bocas daquelas/es que historicamente foram silenciadas/os nos permite contactar outras formas de ver e estar no mundo, de ouvir outras vozes, como a da Anastácia Livre. Quem sabe assim, haveria um caminho de humanização, da constatação da alteridade negra, do pertencimento negro e de uma existência negra a partir da negritude e de referenciais não hegemônicos e não-brancos. 


\section{Pós-verdade: qual o status da "verdade"?}

O conceito de pós-verdade, popularmente conhecida como fake news (traduzido livremente significa "notícias falsas"), surge em 2016 e é definido pela Oxford Dictionaries, departamento da Universidade de Oxford responsável pela elaboração de dicionários e que elege anualmente uma palavra para a língua inglesa, como "circunstâncias nas quais fatos objetivos têm menos influência em moldar a opinião pública do que apelos à emoção e a crenças pessoais" (FÁBIO, 2016).

Gostaria de apresentar algumas reflexões que Tiburi (2017) desenvolve sobre pós-verdade. A autora não define ou enquadra conceitualmente o termo, mas sim, levanta reflexões acerca do tema.

$\mathrm{Na}$ atualidade, nomeado por ela de "pós-episteme", onde compramos e vendemos ideias e conceitos, a autora chama atenção para o fato de que

Nesse mercado já não importa a verdade ou qualquer coisa que tenha a ver com a ideia de uma busca impossível, pelo intangível e pelo mais além. Importam ideias e conceitos a funcionar como próteses cognitivas. Ideias úteis, boas, bonitas e baratas como qualquer mercadoria (TIBURI, 2017, p. 90-91)

Tais ideias e conceitos aparecem e permanecem para satisfazer ao que determinado público quer ouvir, aquilo que seja mais palatável e conveniente de se consumir, tal qual a lógica do mercado capitalista neoliberal, e portanto, de acreditar e reproduzir. Dentro dessa lógica, os intelectuais são aqueles "que organizam o que podemos ou não definir como verdade" (TIBURI, 2017, p. 89) e essa pretensa intelectualidade passou a ser um lugar de disputa de narrativas, e também de poder. Talvez seja pertinente nos perguntar se as pessoas que querem deter o domínio da intelectualidade são representativas da população brasileira.

Tiburi (2017) avalia que os tempos contemporâneos são aqueles dominados por uma pós-verdade e por uma "pós-ética". A pós-verdade simboliza que a verdade perdeu o valor, assim como a ética se tornou disfuncional. Sobre o primeiro conceito ela reflete da seguinte forma:

Ao espectro da verdade pertence o termo pós-verdade. Conceito que coloca em questão o fim da verdade como um valor maior. Se não seu fim, pelo menos está em jogo a sua inutilidade. Com a ideia de pós-verdade, trata-se de falar de uma verdade útil. Da verdade consumível e consumida. A verdade possível quando a forma mercadoria dita que ela mesma é a verdade.

A possibilidade de uma verdade em caixa alta, capaz de nos explicar o desconhecido, não vem mais ao caso. Contentamo-nos com pouco. E esse pouco é a pós-verdade. A verdade que cola, a que vemos circular, a que podemos produzir publicitariamente, a que alimenta a mídia (TIBURI, 2017, p. 97).

Ao refletir sobre o conceito de pós-verdade, Tiburi (2017) mostra a existência de uma relativização da verdade nos tempos atuais, quer dizer, a verdade passa a servir à conveniência de quem fala e de quem ouve. Percebe-se que a autora não coloca em xeque as emoções e os apelos pessoais como faz a definição da Universidade de Oxford em seu dicionário.

\section{Máscaras e fake news: o passado colonial atualizado}

As redes sociais têm forte influência como difusores de notícias falsas e os últimos eventos que mereceram destaque nesse sentido, porque tiveram a propagação de pós-verdades ou fake news, foram a eleição à presidência dos EUA com a campanha de Donald Trump e a saída da Grã-Bretanha da União Européia 
(Brexit). Especula-se que na campanha à presidência do Brasil nas eleições de 2018, o então candidato Jair Bolsonaro, teria utilizado desse método (cf. AMER; NOUJAIM, 2020) e o atual governo brasileiro tem utilizado amplamente essa estratégia. Apresentarei algumas reflexões a partir da colonialidade pensando no contexto brasileiro, pois cabem muitas análises.

A fake news como fenômeno sempre existiu, sendo uma das mais difundidas no nosso país a do "descobrimento do Brasil". Sabe-se que antes dos navegadores portugueses chegarem ao litoral brasileiro já existiam aqui povos indígenas espalhados pelo território conhecido como Abya Yala, cujo significado no idioma Kuna é "Terra madura", "Terra Viva” ou "Terra em florescimento", como um contraponto ao que ficou conhecido como "América", nome dado em homenagem a um dos navegadores colonizadores portugueses Américo Vespúcio ${ }^{10}$. Sendo assim, não seria "descobrir" uma terra que já estava sendo habitada há tempos pelos povos originários, e sim, mais um artifício de encobrimento dos povos indígenas para a aparição da narrativa da pretensa genialidade dos colonizadores quando na realidade se expressa em dominação e expropriação. Isso é uma marca da colonialidade: o epistemicídio, genocídio e extermínio tanto dos conhecimentos quanto das vidas de indivíduos considerados inferiores pelo sujeito colonial.

Grosfoguel, Bernardino-Costa, Maldonado-Torres (2019) dizem:

A partir da elaboração cartesiana, fica clara a ligação entre o conhecimento e a existência. Em outras palavras, o privilégio do conhecimento de uns tem como corolário a negação do conhecimento de outros, da mesma forma que a afirmação da existência de uns tem como lado oculto a negação do direito à vida de outros: a desqualificação epistêmica se converte em instrumento privilegiado da negação ontológica (BERNARDINO-COSTA; MALDONADO-TORRES; GROSFOGUEL apud MALDONADO-TORRES, 2019, p. 12).

A minha hipótese é que a fake news funciona como a máscara moderna, simbolicamente. Vejo semelhanças entre a máscara que funcionava como estratégia de silenciamento e opressão para dar visibilidade à versão contada a partir do ponto de vista do colonizador (que virou a "história oficial") e as fake news. O mecanismo das fake news faz aparecer uma versão da história do mesmo grupo do colonizador, qual seja, um grupo social dominante, com discurso de ódio, racista, patriarcal, poderoso, que trabalha para apagar ou silenciar outras versões que o contradizem ou que o criticam.

A fake news seria uma forma de silenciamento, a função da máscara atualizada, pois continua a tentativa de silenciar grupos historicamente marginalizados para o estardalhaço de outros que sempre se mantiveram no poder. Silenciamento usando as mesmas estratégias de submissão coloniais: morte, necropolítica, empobrecimento, controle, violência e tirania. Encarceramento em massa da população negra, desemprego, sucateamento do SUS (Sistema Único de Saúde), sucateamento da educação pública, destruição da ciência brasileira, desqualificação do discurso científico. Frases ditas pelo atual presidente, por alguns de seus ministros e representantes do Governo Federal como: "Não existe fome no Brasil" (JIMÉNEZ, 2019); "Não existe racismo no Brasil" (SOARES; GULLINO, 2019); "Não existe aquecimento global” (BRASIL, 2019); "Os dados de desmatamento são mentira” sobre a destruição da Amazônia (NOVAES, 2019; URIBE; COLETTA; MOREIRA, 2019). Essas e inúmeras outras declarações absurdas fazem parte de um discurso negacionista e criminoso quando os dados e a realidade são evidentes em mostrar que sim, o racismo existe, a fome existe, o aquecimento global existe, a Amazônia está sendo dizimada (AOS FATOS, 2021 ${ }^{11}$ ). É documentado e são fatos cotidianos. $\mathrm{O}$ atual governo brasileiro tem trabalhado com mentiras e com a fabricação chula de versões da história a fim de manter no poder o mesmo grupo com características coloniais: a hegemonia branca.

10 Conferir mais detalhes em Porto-Gonçalves (2009). Recomendo o programa "Entrevista - Branquitude", no Canal Futura, particularmente o episódio 6, com a pesquisadora Geni Núñez (SOUZA; SCHUCMAN, 2020).

11 Site em que são analisadas todas as declarações feitas por Jair Bolsonaro desde que assumiu a presidência em 2019 até o dia 1 de abril de 2021. 
É um governo autoritário que violentamente tenta nos impor a ocultação dos fatos e evidências, desqualificando a história e os sujeitos. Seria uma tentativa de reencenação do cenário colonial? Com isso, reforça a permanência de uma figura na presidência cujas características são semelhantes àquelas do colonizador: homem, branco, de classe social dominante, ressentida com a perda de privilégios, querendo se manter no poder, pela dominação e ameaça, esgarçando o neoliberalismo e incitando o ódio. Subjugando aqueles que se opõem e/ou são considerados "inferiores" e "desprezíveis", em outras palavras, fazendo funcionar as engrenagens do "racismo de Estado", termo desenvolvido por Foucault (2005).

É um governo que aposta na necropolítica como forma de governo, no desmonte das estruturas públicas e das políticas sociais como agenda e na administração do ódio.

Sendo assim, formulo algumas perguntas:

- Seriam as fake news uma atualização da máscara colonial?

- Será que o mecanismo das fake news traz o rastro da colonialidade?

- A fake news é uma forma atualizada de um discurso colonial?

A resposta para essas perguntas, para mim, é sim. Existem muitas semelhanças entre esses períodos históricos no Brasil - a colonização e o Brasil atual - e a forma como o grupo dominante tenta controlar as camadas tidas como "inferiores" pelo silenciamento, pela dominação e pela violência.

Os dados demonstram a semelhança entre o Brasil colonial e o Brasil de hoje: a permanência e a manutenção da precariedade da vida da população negra brasileira. Ser negro e negra no Brasil é um fator de risco (IPEA, 2020). O Atlas da Violência é um documento anual elaborado em conjunto pelo Instituto de Pesquisa Econômica e Aplicada (IPEA) e pelo Fórum Brasileiro de Segurança Pública e nele, dados sobre violência e segurança pública são mostrados sobre a condição da população brasileira. Resumidamente, uma das principais expressões das desigualdades raciais existentes no Brasil é a concentração dos índices de violência letal na população negra. Os jovens negros são as principais vítimas de homicídios no país e as taxas de mortes de negros vêm crescendo ao longo dos anos, entre os brancos os índices de mortalidade são significativamente menores e, em muitos casos, apresentaram redução quando comparados aos negros. Os homicídios vitimizam, principalmente: homens ( $91,8 \%$ dos casos), jovens ( $53,5 \%$ dos casos), negros ( $75,7 \%$ dos casos) e pessoas com baixa escolaridade (74,3\% dos homens vitimados tinham até sete anos de estudos) (IPEA, 2020). Entre as mulheres ${ }^{12}$, as negras representaram $68 \%$ do total de mulheres assassinadas no Brasil, com uma taxa de mortalidade por 100 mil habitantes de 5,2, quase o dobro quando comparada à das mulheres não negras (IPEA, 2020). Dados como suicídio de jovens revelam que os índices são os mais altos na população negra em detrimento da branca (BRASIL, 2018); desvantagens educacionais são observadas com maior presença na população negra como o atraso escolar e o menor acesso ao ensino superior (IBGE, 2018). Desemprego e analfabetismo são maiores entre as pessoas negras e a conclusão do ensino superior são menores entre negros/as (ROCHA, 2019). Dados como o sofrimento psíquico gerado por conta do racismo em detrimento da aparência física e a dependência química tem destaque para as mulheres negras (ROCHA, 2019). É notório que está historicamente em curso o genocídio da população negra brasileira (NASCIMENTO, 2016).

\section{Considerações finais: no horizonte, o estilhaçamento}

A "versão oficial da História" costuma ser uma versão contada por parte do colonizador e as fake news são uma tentativa de impor distorções diante das versões dos fatos em prol de vantagens para o grupo hegemônico, há aí uma disputa pela narrativa pois na narrativa há poder.

12 Segundo o Atlas da Violência 2018 (IPEA, 2020, p. 46-48), as mulheres sofrem ainda violências que estão associadas à sua saúde tais como o crime de feminicídio que poderia ser dividido em três categorias: o feminicídio reprodutivo (aborto voluntário/involuntário resultando em morte), feminicídio sexual (estupro seguido de morte) e feminicídio doméstico (morte dentro de casa). 
Destaco o seguinte trecho de Chimamanda Adichie, escritora nigeriana, que discursou no TEDGlobal de 2009, sob o título de O perigo da história única:

É impossível falar sobre única história sem falar sobre poder. [...] Como são contadas [as histórias], quem as conta, quando e quantas histórias são contadas, tudo realmente depende do poder. Poder é a habilidade de não só contar a história de outra pessoa, mas de fazê-la a história definitiva daquela pessoa. [...] Comece uma história com as flechas dos nativos americanos, e não com a chegada dos britânicos, e você tem uma história totalmente diferente. Comece a história com o fracasso do estado africano e não com a criação colonial do estado africano e você tem uma história totalmente diferente (ADICHIE, 2019).

Por fim, vejamos o que a Conceição Evaristo (2017), literata, acadêmica e referência nos estudos raciais brasileiros, diz a respeito da imagem que se popularizou da "escrava Anastácia": "eu tenho dito muito que a gente sabe falar pelos orifícios da máscara e às vezes a gente fala com tanta potência que a máscara é estilhaçada. E eu acho que o estilhaçamento é o símbolo nosso, porque a nossa fala força a máscara” (EVARISTO, 2017).

Evaristo (2017) aponta para duas realidades: o silenciamento e a força do estilhaçamento. Portanto, podemos entender que existe ainda o silenciamento da população negra, em particular, das mulheres negras, e, no entanto, há a força, a criatividade e a sabedoria ancestrais que permitiram que a população negra que foi escravizada no Brasil resistisse e sobrevivesse até hoje.

A disputa é por outras versões da história, além da oficial, além das fake news, pois, historicamente, elas partem do ponto de vista hegemônico, do colonizador, do opressor. Nesse sentido, é importante destacar a fala da Conceição Evaristo em sua apresentação na Festa Literária da Periferia (FLUP), realizada no Museu de Arte do Rio (MAR) em outubro de 2019, que aponta para a falta que o sujeito negro diaspórico tem sobre a sua própria história, um não-lugar, que vive a procura do tempo que lhe foi roubado. Além disso, Conceição Evaristo fala sobre reconstruirmos um tempo que não tivemos. A literatura negra ficcional é uma forma de recuperar um tempo, uma história que não se sabe, que foi perdida. Ana Maria Gonçalves que escreveu o romance Um defeito de cor de 2006 disse na mesma ocasião que somos fruto de uma ficção contada pelos brancos e que temos que nos reinventar. $\mathrm{O}$ direito à memória, o direito à nossa história, o direito à nossa identidade, são aspectos que o racismo estrutural tenta negar acesso à população negra brasileira.

Em suma, tornar visíveis versões da história por parte daqueles que foram e são silenciados, em especial as mulheres negras, é uma forma de causar fissuras e estilhaçamentos nas máscaras coloniais modernas.

\section{Referências bibliográficas}

ADICHIE, Chimamanda Ngozi. O perigo de uma história única. São Paulo: Companhia das Letras, 2019.

ALMEIDA, Silvio. Racismo: prisma social. [Palestra] Programa Evidências das Culturas Negras. Museu do Amanhã. 18 de jun. 2019a.

ALMEIDA, Silvio. Racismo estrutural. São Paulo: Sueli Carneiro; Pólen, 2019b.

ALMEIDA, Silvio; ONODA, Camilo. Racismo Estrutural e Estado de Direito. [Curso]. Rio de Janeiro. 21 de set. 2019c.

AMER, Karim; NOUJAIM, Jehane. The Great Hack. [Privacidade Hackeada]. [Obra cinematográfica, documentário]. Netflix, 2020.

BRASIL. Ministério da Saúde. Universidade de Brasília. Óbitos por suicídio entre adolescentes e jovens negros 2012 a 2016. Brasília: MS, 2018.

BRASIL. Ministério das Relações Exteriores. Araújo nega aquecimento global e diz que 'ditadura climática' é usada para atacar Brasil. 11 set 2019. Disponível em: <http://www.itamaraty.gov.br/pt-BR/sem-categoria/20837-araujo-nega- 
aquecimento-global-e-diz-que-ditadura-climatica-e-usada-para-atacar-brasil-reuters-11-de-setembro-de-2019>. Acesso em: 13 jan. 2020.

CARNEIRO, Sueli. Escritos de uma vida. Belo Horizonte (MG): Letramento, 2018.

CRUZ, Yhuri. Monumento à voz de Anastácia. 04/06/2019. Disponível em: <https://yhuricruz.com/2019/06/04/ monumento-a-voz-de-anastacia-2019/> Acesso em: 19 dez. 2019.

SOUZA, Karen; SCHUCMAN, Lia Veiner. Entrevista - Braquitude. Canal Futura, 5 out. 2020. (Programa de televisão e online). Disponível em: <https://www.futura.org.br/nova-temporada-do-entrevista-debate-o-conceito-debranquitude-e-o-papel-da-populacao-branca-na-manutencao-do-racismo-no-brasil/>. Acesso em: out.2020.

EVARISTO, Conceição; GONÇALVES, Ana Maria. Mesa: A Carolina que habita em nós. [Debate] Mediação; Mirian Cristina dos Santos. Festa Literária das Periferias (FLUP) 2019. Museu de Arte do Rio (MAR). Rio de Janeiro. 19 out. 2019.

EVARISTO, Conceição. Conceição Evaristo: "Nossa fala estilhaça a máscara do silêncio". Carta Capital, 13 de mai. 2017. Entrevista. Disponível em: <https://www.cartacapital.com.br/sociedade/conceicao-evaristo-201cnossa-falaestilhaca-a-mascara-do-silencio201d/>. Acesso em: agosto de 2019.

FÁBIO, André Cabette. O que é 'pós-verdade', a palavra do ano segundo a Universidade de Oxford. NEXO Jornal. 16 de nov de 2016. Disponível em: <https://www.nexojornal.com.br/expresso/2016/11/16/O-que-\%C3\%A9\%E2\%80\%98p\%C3\%B3s-verdade\%E2\%80\%99-a-palavra-do-ano-segundo-a-Universidade-de-Oxford> Acesso em: agosto de 2019.

FANON, Frantz. Pele negra, máscaras brancas. SILVEIRA, Renato da. (Trad.). Salvador: EDUFBA, 2008.

FEDERICI, Silvia. Sobre o significado de "gossip". In:___. Mulheres e a caça às bruxas. Boitempo, 2019. Disponível em: <https://www.nexojornal.com.br/estante/trechos/2019/09/19/\%E2\%80\%98Mulheres-e-a-ca\%C3\%A7a-\%C3\%A0sbruxas\%E2\%80\%99-das-ra\%C3\%ADzes-\%C3\%A0-atualidade>. Acesso em: 30 set. 2019.

FOUCAULT, Michel. Em defesa da sociedade: Curso do Collège de France (1975-76); GALVÃO, Maria Ermantina. (Trad.). São Paulo: Martins Fontes, 2005.

FOUCAULT, Michel. Vigiar e punir: nascimento da prisão; tradução de Raquel Ramalhete. 37. ed. Petrópolis: Vozes, 2009. GONÇALVES, Ana Maria. Um defeito de cor. Rio de Janeiro: Record, 2017.

GROSFOGUEL, Rámon; BERNARDINO-COSTA, Joaze; MALDONADO-TORRES, Nelson (orgs.). Decolonialidade e pensamento afrodiaspórico. Belo Horizonte: Autêntica Editora, 2019.

IBGE. Instituto Brasileiro de Geografia e Estatística. Estatísticas de gênero: indicadores sociais das mulheres no Brasil. Rio de Janeiro: IBGE, 2018.

IPEA. Instituto de Pesquisa Econômica Aplicada; Fórum Brasileiro de Segurança Pública (Org.). Atlas da violência 2020. Brasília; Rio de Janeiro; São Paulo: IPEA; FBSP, 2020.

IPEA. Instituto de Pesquisa Econômica Aplicada. Atlas da violência 2018. Rio de Janeiro: IPEA; FBSP, 2018.

JESUS, Camila Moreira de. Branquitude x branquidade: uma análise conceitual do ser branco. Trabalho apresentado no III Encontro Baiano de Estudos em Cultura. Anais... Salvador, Bahia, 2012.

JIMÉNEZ, C. Bolsonaro: Falar que se passa fome no Brasil é uma grande mentira, é um discurso populista. El País. 19 jul 2019. Disponível em: <https://brasil.elpais.com/brasil/2019/07/19/politica/1563547685_513257.html>. Acesso em: 13 jan. 2020.

KILOMBA, Grada. Memórias da plantação: Episódios de racismo cotidiano. OLIVEIRA, Jess. (Trad.). 1. ed. Rio de Janeiro: Cobogó, 2019.

LIMA, Fátima. Sobre dores, saudades e (re)existências. Dossiê: Raça, interseccionalidade e violência: corpos e processos de subjetivação em mulheres negras e lésbicas. Cadernos de Gênero e Diversidade, v.4, n.2 - Abr.-Jun., 2018.

LIMA, Fátima; ANDRADE, Ludmilla Lis. Racismo e sociogenia em Frantz Fanon: diálogos com Grada Kilomba e Conceição Evaristo. In.: MAGNO, Patrícia Carlos; PASSOS, Rachel Gouveia. (Orgs.). Direitos humanos, saúde mental e racismo: diálogos à luz do pensamento de Frantz Fanon. Rio de Janeiro: Defensoria Pública do Estado do Rio de Janeiro, 2020.

MBEMBE, Achille. Necropolítica: biopoder, soberania, estado de exceção, política da morte. 2a edição. São Paulo: N-1 edições, 2018. 
MBEMBE, Achille. Crítica da razão negra. LANÇA, Marta. (Trad.). Portugal: Antígona, 2014.

NASCIMENTO, Abdias. O genocídio do negro brasileiro: processo de um racismo mascarado. $3^{a}$. ed. São Paulo: Perspectivas, 2016.

NOVAES, Marina. "Constrangimento” com Bolsonaro por dados de desmatamento derruba diretor do Inpe. El País. 02 ago 2019. Disponível em: <https://brasil.elpais.com/brasil/2019/08/02/politica/1564759880_243772.html> Acesso em: 13 jan. 2020.

ODA, Ana Maria Galdini Raimundo. Escravidão e nostalgia no Brasil: o banzo. Rev. Latinoam. Psicopat. Fund., São Paulo, v.11, n.4, p.735-761, dez.2008. Disponível em: <http://www.scielo.br/scielo.php?pid=S141547142008000500003\&script=sci_arttext>. Acesso em: jan. 2020.

PEREIRA, Júlio César Medeiros da Silva. À flor da terra: o cemitério dos Pretos Novos no Rio de Janeiro. Rio de Janeiro: Garamond: IPHAN, 2007.

PORTO-GONÇALVES, Carlos Walter. Entre América e Abya Yala. 11 junho 2009. Disponível em: <http://hernehunter. blogspot.com/2009/07/entre-america-e-abya-yala.html> Acesso em: 25 abril 2021.

RIBEIRO, Djamila. Lugar de fala. São Paulo: Sueli Carneiro; Pólen, 2019.

ROCHA, Camilo. O impacto do racismo na saúde mental da população negra. Nexo Jornal. 26 jan 2019. Disponível em: <https://www.nexojornal.com.br/expresso/2019/01/26/O-impacto-do-racismo-na-sa\%C3\%BAde-mental-dapopula\%C3\%A7\%C3\%A3o-negra>. Acesso em 28/01/2019.

SANTOS, Boaventura de Sousa. Aula 2: Construção de diálogos entre saberes a partir das Epistemologias do Sul. In: Na oficina do sociólogo artesão: aulas 2011-2016. São Paulo: Cortez, 2018.

SCHWARCZ, Lilia. O sol e a sombra. Ou como inventar uma história pela metade. Nexo Jornal. 7 out. 2019. Disponível em: <https://www.nexojornal.com.br/colunistas/2019/O-sol-e-a-sombra.-Ou-como-inventar-uma-hist\%C3\%B3riapela-metade>. Acesso em: out. 2019.

SLAVE IMAGES. A visual record of the african slave trade and slave life in the early african diaspora. Disponível em: <http://www.slaveryimages.org/s/slaveryimages/page/welcome>. Acesso em: ago. 2019.

SOARES, Jussara; GULLINO, Daniel. Novo presidente da Fundação Palmares nega existência de racismo e pede fim do movimento negro. O Globo. 27/11/2019. Disponível em: <https://oglobo.globo.com/cultura/novo-presidente-dafundacao-palmares-nega-existencia-de-racismo-pede-fim-do-movimento-negro-1-24104072>. Acesso em: 13 jan. 2020 .

TIBURI, Marcia. Pós-verdade, pós-ética: uma reflexão sobre delírios, atos digitais e inveja. In: DUNKER, Christian [et. al.]. Ética e pós-verdade. Porto Alegre: Dubliense, 2017. p. 87-113.

URIBE, Gustavo; COLETTA, Ricardo Della; MOREIRA, Matheus. Bolsonaro diz que desmatamento é cultural no Brasil e não acabará. Folha de São Paulo. 20 nov 2019. Disponível em: <https://www1.folha.uol.com.br/ambiente/2019/11/ bolsonaro-diz-que-desmatamento-e-cultural-no-brasil-e-nao-acabara.shtml>. Acesso em: 13 jan. 2020. 